\title{
Probabilistic flood inundation mapping at ungauged streams due to roughness coefficient uncertainty in hydraulic modelling
}

\author{
George Papaioannou ${ }^{1}$, Lampros Vasiliades ${ }^{1}$, Athanasios Loukas ${ }^{1}$, and Giuseppe T. Aronica ${ }^{2}$ \\ ${ }^{1}$ Laboratory of Hydrology and Aquatic Systems Analysis, Department of Civil Engineering, University of Thessaly, \\ Pedion Areos, 38334 Volos, Greece \\ ${ }^{2}$ Department of Civil Engineering, Computer Science, Building, Environmental Science, and Applied Mathematics, \\ University of Messina, Contrada Di Dio, 98166 Villaggio S. Agata, Messina, Italy \\ Correspondence to: George Papaioannou (gpapaioa@uth.gr)
}

Received: 28 November 2016 - Revised: 7 March 2017 - Accepted: 3 April 2017 - Published: 26 April 2017

\begin{abstract}
Probabilistic flood inundation mapping is performed and analysed at the ungauged Xerias stream reach, Volos, Greece. The study evaluates the uncertainty introduced by the roughness coefficient values on hydraulic models in flood inundation modelling and mapping. The wellestablished one-dimensional (1-D) hydraulic model, HECRAS is selected and linked to Monte-Carlo simulations of hydraulic roughness. Terrestrial Laser Scanner data have been used to produce a high quality DEM for input data uncertainty minimisation and to improve determination accuracy on stream channel topography required by the hydraulic model. Initial Manning's n roughness coefficient values are based on pebble count field surveys and empirical formulas. Various theoretical probability distributions are fitted and evaluated on their accuracy to represent the estimated roughness values. Finally, Latin Hypercube Sampling has been used for generation of different sets of Manning roughness values and flood inundation probability maps have been created with the use of Monte Carlo simulations. Historical flood extent data, from an extreme historical flash flood event, are used for validation of the method. The calibration process is based on a binary wet-dry reasoning with the use of Median Absolute Percentage Error evaluation metric. The results show that the proposed procedure supports probabilistic flood hazard mapping at ungauged rivers and provides water resources managers with valuable information for planning and implementing flood risk mitigation strategies.
\end{abstract}

\section{Introduction}

Natural hazards have caused significant damages to natural and manmade environments during the last few decades. Floods are among the most destructive water-related hazards and are the main responsible for the loss of human lives, infrastructure damages and economic losses (Tsakiris, 2014). Nowadays, there is a rising global awareness for flood damage mitigation due to the increase in frequency, magnitude, and intensity of flood events (Hall et al., 2014). Hence, identifying flood-prone areas could be very useful in water resources management strategies against floods. Digital Elevation models (DEMs) and the DEM-derived geomorphological and hydrological attributes has become a standard tool for flood-prone areas identification (Noman et al., 2001; Papaioannou et al., 2015). However, for accurate flood modelling and inundation mapping a hydraulic-hydrodynamic model is required to simulate flood characteristics such as flood inundation extent and water depth. Floodplain mapping and flood risk assessment have been mainly assessed using one-dimensional (1-D) and two-dimensional (2-D) hydraulic models (e.g.; Aronica et al., 2002; Horritt et al., 2007; Costabile and Macchione, 2015; Papaioannou et al., 2016). These models are able to simulate floodplain inundation and river hydraulics as demonstrated in many studies (e.g. Horritt et al., 2007; Di Baldassarre et al., 2010; Sarhadi et al., 2012; Domeneghetti et al., 2013; Dottori et al., 2013; Dimitriadis et al., 2016). However, most of these studies have been carried out at gauged watersheds using information from hydrometric stations with discharge data and stage/discharge relationships which limit the application of these models in accurate 
estimation of flood spatial extent (Bates et al., 2006; Aggett and Wilson, 2009) especially in urban and suburban areas.

Hydraulic modelling of floods is affected by many sources of uncertainty (i.e. input data, model structure, model parameters). Furthermore, several factors in each source (type) of uncertainty affect the flood modelling process and the mapping results that increase/decrease the uncertainty of the outcome. Estimation of Digital Elevation Models without errors is impossible in flood inundation modelling and mapping, especially in complex terrains (Tsubaki and Fujita, 2010; Papaioannou et al., 2016). Photogrammetric and ground surveying techniques are the most common sources for DEM creation using topographic data. However, especially in complex landscapes, flood inundation modelling using these techniques could put limitations in the coverage of the study area and in the accuracy of the produced DEM (Md Ali et al., 2015; Teng et al., 2015). The development of the new spatial tools to generate high-resolution digital elevation models might overcome these restrictions and could enable construction of valid hydraulic models for floodplain inundation mapping. In recent years, new techniques, methods and instruments arise such as the Terrestrial Laser Scanners (TLS) or Airborne Light Detection and Ranging (LIDAR), and/or the Synthetic Aperture Radar (SAR) that could produce high resolution DEMs. This additional spatial information, produced by TLS, are advantageous when compared to other techniques and could improve flood inundation especially in urban and suburban areas with complex river and riverine topography (Sampson et al., 2012). Another important factor in floodplain modelling and inundation mapping is the applied hydraulic modelling structure (1-D, 2-D, 1-D/2D). One dimensional (1-D) hydraulic models are the most common method for flood simulation and flood inundation mapping because of their simplicity, least amount of input data and low computational power (e.g. Pappenberger et al., 2005; Kourgialas and Karatzas, 2014; Teng et al., 2017). Furthermore, two dimensional (2-D) hydrodynamic models have been applied in recent studies, due to improvements on model structure and on model parameter estimation methods (Cook and Merwade, 2009; Tsakiris and Bellos, 2014; Costabile and Macchione, 2015; Shen et al., 2015; Teng et al., 2017). Finally, the capabilities of coupled 1-D/2-D models in flood inundation modelling has gained large acceptance in the scientific community (Apel et al., 2009; Liu et al., 2015; Teng et al., 2017).

Evaluation of flood inundation areas is usually performed by deterministic and/or probabilistic hydraulic approaches (Teng et al., 2017). Deterministic procedures rely on the calibration principles of a hydraulic model to a specified observed historical flood episode, and the application of the calibrated model to different flood episodes or to typical design floods for engineering applications. However, deterministic approaches depend on the following crucial assumptions: (1) ability of the hydraulic model to simulate satisfactorily the river dynamics and to estimate accurately the floodplain inundation areas; (2) model parameter stability or time stationarity of model parameters which means that model parameter values (i.e. roughness coefficients) estimated by calibration are suitable for application of the model in completely different conditions from those of the calibration event; (3) all information (e.g. input flood hydrographs, stage-discharge relationships, runoff measurements, validation areas) used in hydraulic simulations is error-free (Domeneghetti et al., 2013). Hence, based on the above sources of uncertainty, to overcome these assumptions probabilistic approaches are applied to flood inundation modelling and mapping. Recent studies advocate the use of probabilistic instead of the deterministic approaches for three main reasons (Di Baldassarre et al., 2010; Domeneghetti et al., 2013; Dottori, et al., 2013; Romanowicz and Kiczko, 2016; Alfonso et al., 2016): (1) the uncertainty in hydrologic/hydraulic modelling process could not be neglected; (2) uncertainty should always be accounted and evaluated in the presentation of the results for a comprehensive analysis; (3) probabilistic flood inundation maps could assist water resources managers to design and support flood mitigation strategies. Thus, deterministic procedures might give erroneous results in flood inundation mapping that could have large impacts, if they are used for management purposes.

Classification of uncertainty can be separated in the two following types: (1) natural or aleatory uncertainty which is the natural randomness in a process and is introduced by the natural variability of floods and (2) epistemic uncertainty which is the scientific uncertainty in the model of the process and is associated with inadequate knowledge of the system and with the modelling approach (e.g. input data, employed model structure, model parameters; Apel et al., 2004; Merz and Thieken, 2005). Probabilistic approaches have been used in many studies to model parameter uncertainty on hydraulic models due to roughness coefficient values (e.g. Aronica et al., 2002; Pappenberger et al., 2005). The probabilistic process of floodplain mapping is based on hydraulic model setup, and ensemble simulation for other observed or design flood hydrographs (e.g. Bates et al., 2004). The probabilistic approach is not relying on the adopted hydraulic model structure (i.e. physically-based 2-D model) and subsequently in the assumption that a complex hydraulic model could represent the dynamics of the river and floodplain with high accuracy. The latter was demonstrated by Papaioannou et al. (2016) for Xerias River, Volos, Greece where several 1$\mathrm{D}$ and 2-D hydraulic-hydrodynamic models have been evaluated for flood inundation and mapping. Based on the results of that study, 1-D hydraulic models have similar performance as the 2-D models when high quality data (derived from TLS-LiDAR DEM) are used for the hydraulic model setup (model construction; Papaioannou et al., 2016). Furthermore, 1-D hydraulic modelling is commonly used in computationally intensive applications such as Monte Carlo analysis and probabilistic mapping of outputs (Di Baldassarre et al., 2010; Alfonso et al., 2016; Teng et al., 2017). 


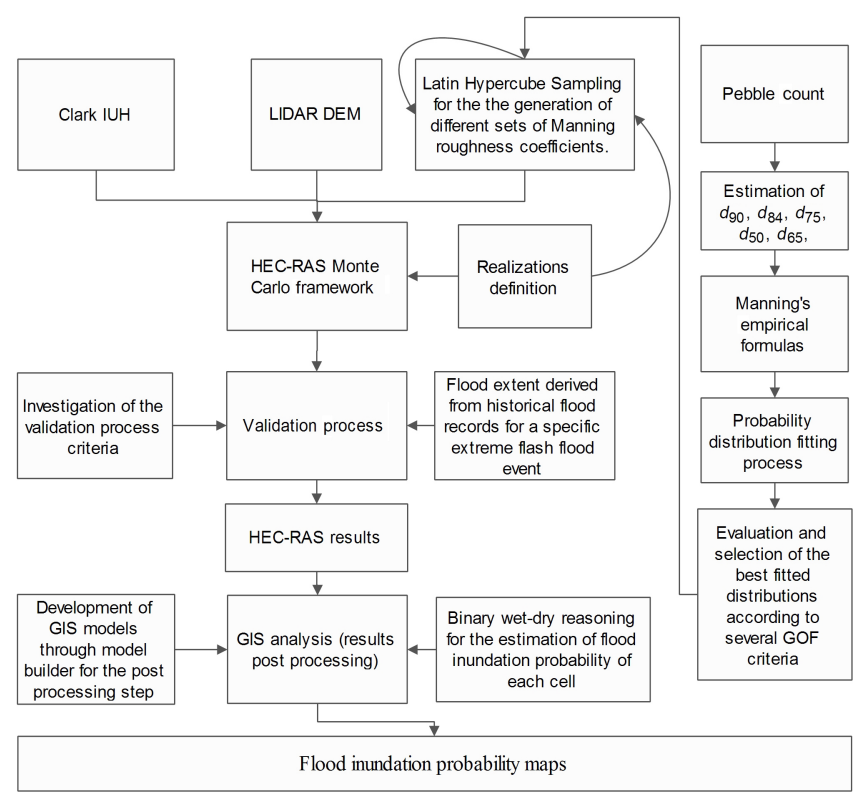

Figure 1. Flow diagram of the proposed framework.

In this study, a generic procedure for uncertainty analysis of floodplain mapping due to roughness coefficient is developed for the ungauged Xerias river, Volos, Greece. The HECRAS 1-D hydraulic-hydrodynamic model is used to assess the uncertainty introduced by the roughness coefficient using Monte-Carlo simulations. Manning's $n$ roughness coefficient initial ranges are estimated using several empirical formulas employing pebble count and field survey data, and various theoretical probability distributions are fitted and evaluated using several goodness-of-fit criteria. Latin Hypercube sampling has been used for the generation of different sets of Manning roughness coefficients and several realizations of flood inundation maps are created. The uncertainty is estimated based on a calibration process which is based only on the flood extent derived from historical flood records for an observed extreme flash flood event.

\section{Methodology}

In this study special attention is given to develop a generic procedure for probabilistic flood inundation mapping at ungauged river reaches. Figure 1 presents the flow diagram of the proposed procedure and the steps needed for uncertainty mapping of flood inundation areas. The principal parts of the method, which are analysed in the following subsections, are: the study area with the river reach and the pebble count field survey, the theoretical probability distribution fitting on the Manning's roughness coefficient values estimated using several empirical formulae and the hydraulic modelling for flood inundation probability mapping using the HEC-RAS 1-D model (Fig. 1).

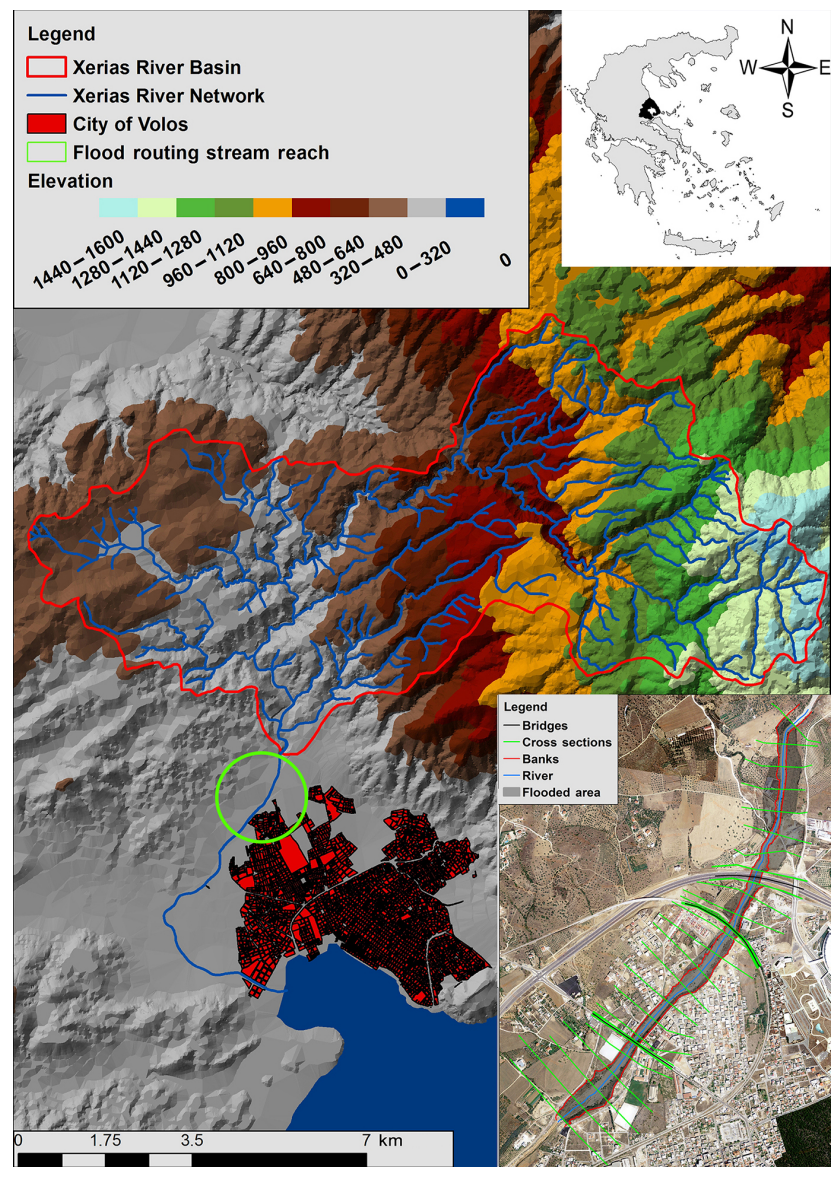

Figure 2. Study area and the selected stream reach with the observed flooded area.

\subsection{Study area}

The study area is located at the ungauged Xerias river basin, Greece (Fig. 2). Details on the watershed characteristics and the observed historical flood event of the 9 October 2006 could be found in recent studies (Papaioannou et al., 2015, 2016). This flood event is simulated using the Clark Instantaneous Unit Hydrograph (CIUH: Clark, 1945) on the extreme observed rainfall hyetograph and the simulated flood extent is compared with the validation area. The later refers to the observed flooded area (Fig. 2) estimated with the use of historical data and records (flood recordings from newspapers, several authorities, local interviews and testimonies of flood victims; Papaioannou et al., 2016). Figure 2 also shows the study river reach, with length of $2.2 \mathrm{~km}$, where hydraulic simulations are performed. For this particular river segment, a high resolution digital terrain model is constructed to extract details of channel topography for accurate hydraulic modelling. Specifically, the construction of a high resolution DEM for flood inundation mapping applications is important because the hydraulic-hydrodynamic model estimates the water surface elevations using the cross-sections topography. 
Therefore, terrain elevations are subtracted from simulated water surface elevations to simulate flood depth and flooded area (Noman et al., 2001, 2003). High quality DEMs could disclose channel geometry and enhance hydraulic model efficiency on flood spatial extent. Hence, high-resolution DEMs could improve the performance of the applied hydraulic models for floodplain inundation modelling and mapping. Many studies have evaluated hydraulic model performance and especially HEC-RAS using high resolution DEM constructed from Light Detection and Ranging (LiDAR) and Synthetic Aperture Radar (SAR) data (Sarhadi et al., 2012; Marzocchi et al., 2014; Md Ali et al., 2015; Podhoranyi and Fedorcak, 2015; Papaioannou et al., 2016). These studies demonstrated that LiDAR data facilitate topographic representation of the stream channel, topography and hydraulic model accuracy (Aggett and Wilson, 2009; Papaioannou et al., 2013).

The Processed LIDAR (bare earth) DEM was derived from high resolution TLS point cloud data with the use of geomorphological filters, expert knowledge and GIS operations. The Optech ILRIS 3-D laser scanner was used to create the point cloud data when weather and hydraulic conditions were acceptable for unbiased sampling. A zigzag pattern was followed to scan the selected area with a total of 86 scans from both sides of the river banks. Details on the pre and post processing methodology of the TLS Digital Terrain Model (Processed LiDAR DEM) could be found in Papaioannou et al. (2013). The use of LiDAR data in this study has obvious advantages when compared with the traditional ground surveying techniques. Some of these pros is the classification of the surface prior to surface generation in point clouds that indicate elevations of LiDAR footprints, and the point cloud preprocessing (removal of vegetation, obstacles etc.; Papaioannou et al., 2013). After the LiDAR DEM construction, the DEM is overlaid with local imagery to provide a highly realistic virtual 3-D environment for optimal locating and digitizing cross-sections in HEC-RAS model. Figure 2 shows the selected cross-sections generated with this procedure and based on the existing hydraulic structures and characteristics of the study river reach. Furthermore, the visual information contained in the derived terrain allowed for optimum selection of an initial roughness coefficient value for the study river reach.

\subsection{Hydraulic modelling}

Hydraulic flood modelling and subsequent floodplain mapping require the use of the most capable and suitable tools according to the EU Directive on floods (2007/60). The 1-D modelling approach is usually followed due to minor input data requirements and low computational resources as well as the proven accuracy in flood inundation processes (Tsakiris, 2014). However, in landscapes with complicated channel geometry and river network, 1-D-modelling approach might be inadequate and could produce significant errors. Therefore, in areas of complex terrain, different modelling approaches should be investigated and the most suitable one should be selected for flood modelling and mapping (Papaioannou et al., 2016). Furthermore, recent benchmark studies on assessing hydraulic model structures have shown that complex 2-D models with high resolution grids show marginal improvements on flood estimation and inundation mapping and exhibit instabilities as grid size moves closer to the scale of processes under investigation (Horritt and Bates, 2002; Dimitriadis et al., 2016; Papaioannou et al., 2016). Lastly, 2-D hydraulic/hydrodynamic models are not preferred at ungauged river reaches because they are more complicated, require extensive parameterization to perform satisfactorily on floods modelling and due to vast uncertainty of the flood process. Hence, the 1-D hydraulic model HECRAS, is adopted for use on the probabilistic flood inundation mapping framework.

The well-known HEC-RAS one dimensional (1-D) hydraulic-hydrodynamic model has been developed by the Hydrologic Engineering Center (HEC) of United States Army Corps of Engineers (Brunner, 2016a). The HEC-RAS model has been used in many studies of river and floodplain analysis (e.g. Di Baldassarre et al., 2010; Dottori et al., 2013; Alfonso et al., 2016) to simulate flow over several hydraulic structures (culverts, weirs, road overtopping etc) and to calculate water surface profiles for several system formulations. Channel geometry and flow data for specified formulations could be used for comparisons between existing and/or future channel and flow simulations. Optional capabilities in HECRAS allow for mixed flow regime calculations, and flow distribution calculations via segmentation of the cross-section in left and right overbanks, based on geometric, hydraulic and roughness characteristics. HEC-RAS can simulate both steady and unsteady flow conditions in river channels and floodplains. Steady state flow conditions are calculated based on the one-dimensional energy equation, whereas unsteady state flow conditions are simulated based on the full dynamic 1-D Saint Venant Equation. Finally, the delineation of the flooded area is based on the intersection of the modelled water levels with the floodplain surface (Brunner, 2016a). The hydraulic modelling procedure usually includes three stages: namely the pre-processing, HEC-RAS modelling and postprocessing.

In pre-processing, the channel geometry required by HECRAS is estimated using HEC-GEORAS and the LiDAR derived DEM. The stream centerline, riverbanks, levee and terrain cross-sections, are estimated in this stage. Each crosssection is manually checked and the banks are relocated on flat areas to ensure accuracy with the LiDAR DEM. Initially, cross-sections were generated for variable length (Fig. 2) as explained in the previous section and because water surface profiles are found to be highly sensitive to crosssection spacing and DEM accuracy (Sarhadi et al., 2012), finally cross-sections are interpolated at intervals of $1 \mathrm{~m}$. All 
Table 1. Empirical relationships proposed in the international literature for assessing Manning's roughness coefficient $(n)$ values.

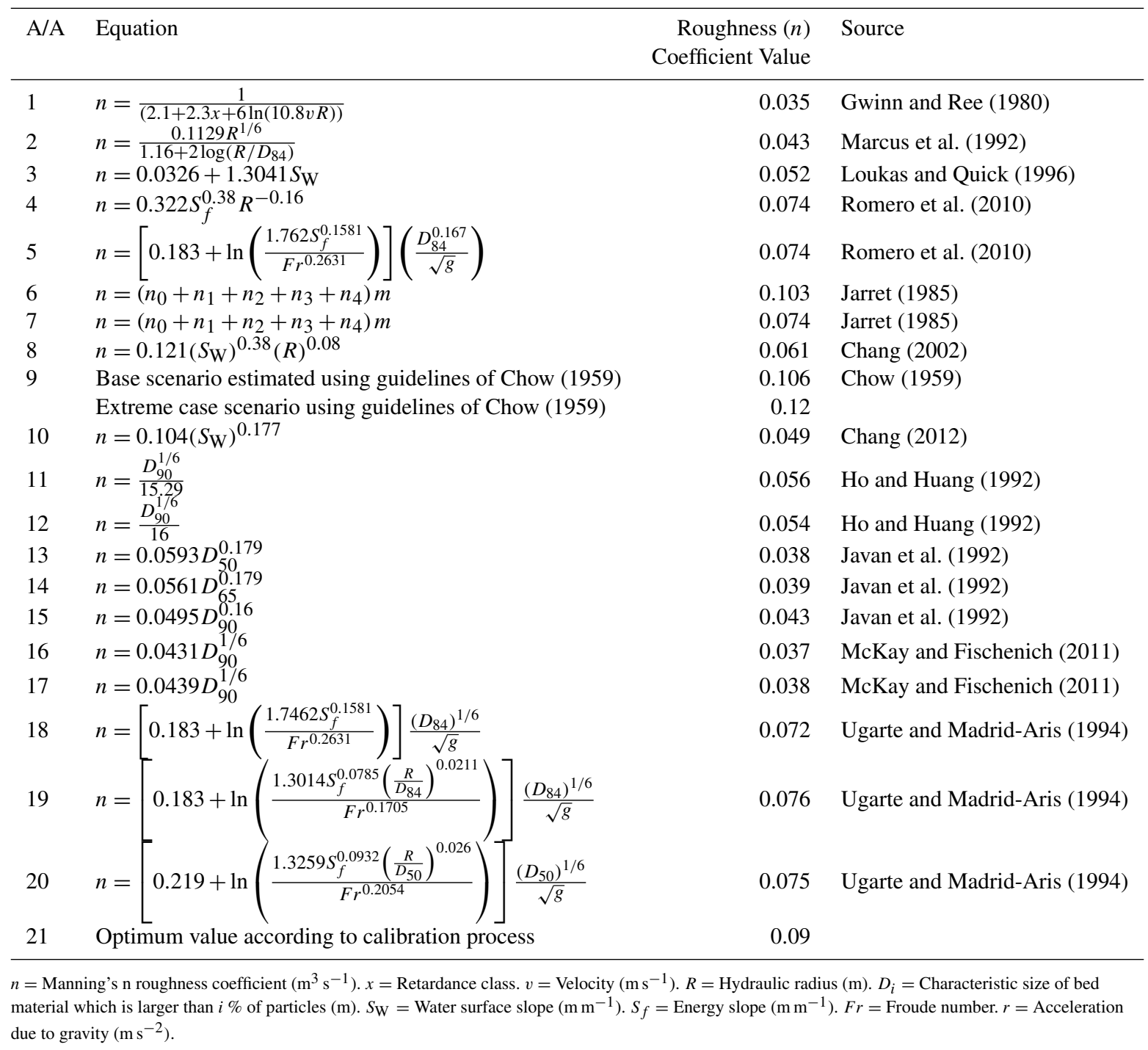

pre-processed river and floodplain geometry was inserted to HEC-RAS.

In HEC-RAS modelling, flood inundation mapping with HEC-RAS is performed. This stage requires input data such as flow data, boundary conditions, cross-section and floodplain topography, and the friction parameter as explained by the Manning's roughness coefficient $(n)$ values. The input flow hydrograph is estimated with the Clark Instantaneous Unit Hydrograph (CIUH) for the observed extreme hyetograph of the flood event on 9 October 2006. The CIUH is based on time-area unit hydrograph theory and establishes a relationship between the travel time and a portion of a basin that may contribute runoff during that travel time. The time-area histogram is a translation hydrograph because the volume of water on each area within the basin is simply "translated" to the outlet using the associated travel time for the translation time. Then the translation unit hydrograph is routed through a linear reservoir with a routing coefficient (McCuen, 2005). All flow simulations were done using the upstream estimated discharge as input to HEC-RAS model for hydraulic simulation, while the friction slope estimated with the LiDAR DEM was used as downstream boundary condition and with default contraction and expansion coefficients of 0.1 and 0.3 , respectively (Brunner, 2016b). Topographic characteristics of the cross sections and the floodplain are estimated based on the LiDAR DEM. The roughness coefficients values are initially estimated based on field assessment of the type and size of the bed, banks and overbank material of the channel (Coon, 1998). However, due to the large uncertainty associated with the roughness values the pebble count method as shown in Fig. 1 is used for the estimation of the final Manning's $n$ values. The assessment of particle size in gravel-bed and cobble-bed torrents is mainly estimated using pebble count methods (Bunte et 
Table 2. Evaluation criteria of the applied theoretical probability distributions.

\begin{tabular}{lrrr|rr}
\hline & \multicolumn{3}{c|}{ Goodness of fit statistics } & Goodness of fit criteria \\
\cline { 2 - 6 } Distributions & Kolmogorov-Smirnov & Cramer-von Mises & Anderson -Darling & AIC & BIC \\
\hline Normal & 0.1307 & 0.1008 & 0.6818 & 97.5191 & -95.337 \\
Lognormal & 0.1458 & 0.0793 & 0.5153 & 101.437 & -99.2552 \\
Exponential & 0.4239 & 0.8333 & 4.1749 & 74.8262 & -73.7352 \\
Gamma & 0.131 & 0.08 & 0.5303 & 100.762 & -98.5796 \\
Beta & 0.1304 & 0.0801 & 0.5327 & 100.673 & -98.4905 \\
Uniform & 0.3358 & 0.7077 & inf & NA & NA \\
Logistic & 0.1292 & 0.0867 & 0.625 & 96.6285 & -94.4465 \\
Cauchy & 0.2002 & 0.137 & 0.9604 & 87.7592 & -85.5771 \\
Weibull & 0.1296 & 0.0848 & 0.5794 & 98.6621 & -96.48 \\
\hline
\end{tabular}

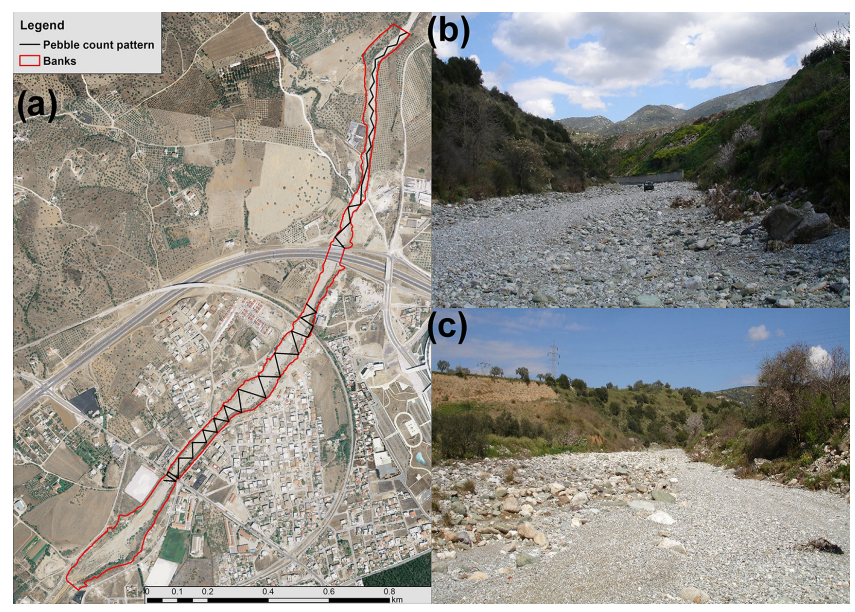

Figure 3. Pebble count field survey: Wolman pebble count method (a) and typical examined river bed materials $(\mathbf{b}, \mathbf{c})$.

al., 2009; Ward et al., 2016). Figure 3 presents the Wolman pebble count method with a step-toe procedure and following a zigzag pattern for Xerias river reach. Based on the field survey for the larger part of the study reach (Fig. 3) determination of particle size was identified for predefined size diameters of $d_{50}, d_{65}, d_{75}, d_{84}$ and $d_{94}$. The selection of the predefined size diameters is based on the use of empirical equations proposed in the international literature for estimating Manning's roughness coefficient $(n)$ values from known particle sizes (Table 1). Several empirical relationships were applied according to Table 1 for the estimation of roughness coefficient values. For probabilistic flood inundation mapping, several theoretical probability distributions (e.g. Normal, Lognormal, Gamma, Logistic) were fitted to the initial values and evaluated using several goodness-of-fit statistics and criteria (Table 2). The best fitted theoretical distribution was selected for inclusion in the generic procedure for uncertainty estimation of flood inundation area due to roughness coefficient values.
In post-processing, the HEC-RAS outputs of the hydraulic modelling process are imported into a GIS, for graphical representation of the results with the other geoinformation such as the constructed DEM. Hence, post-processing involves generation of different themes and maps and is the visualization process of the HEC-RAS modelling stage. In this study the post-processing is included and analysed on the developed HEC-RAS Monte-Carlo framework.

\subsection{HEC-RAS Monte-Carlo framework}

A framework for automated HEC-RAS uncertainty analysis and implementation is developed in this study at ungauged watersheds. The framework is capable to provide Monte-Carlo simulation experiments within the HEC-RAS and automated data handling and manipulation procedures (Fig. 1). The required inputs to HEC-RAS are called from the framework using VBA routines based on the work of Goodell (2014). The user must specify the number of desired acceptable simulations (realizations) for probabilistic flood inundation mapping and the selected statistical criteria based on the inherent calibration process for uncertainty analysis due to roughness values. Latin Hypercube Sampling (LHS) of the best fitted theoretical probability distribution is executed to generate large Manning roughness coefficients data sets which were automatically imported into HEC-RAS. LHS ensure that all parts of the probability distribution are represented in the generated samples and for $\mathrm{n}$ random numbers from the distribution, the distribution is divided into $n$ intervals of equal probability $1 / n$ (Millard, 2013). Latin Hypercube Sampling is also known as stratified sampling without replacement (McKay et al., 1979). Because of the difficulties in the evaluation accuracy process at the ungauged river reaches, qualitative criteria are mainly used for fulfilling this target. Usually these criteria are based on the matching agreement of the $2 \times 2$ contingency table (or confusion matrix) using observed and simulated inundation areas and answers the question of whether the flood extent reflected in the map is the same on the ground (Horritt and Bates, 2002, 2001; Aronica et al., 2002; Alfieri et al., 2014; Papaioannou 


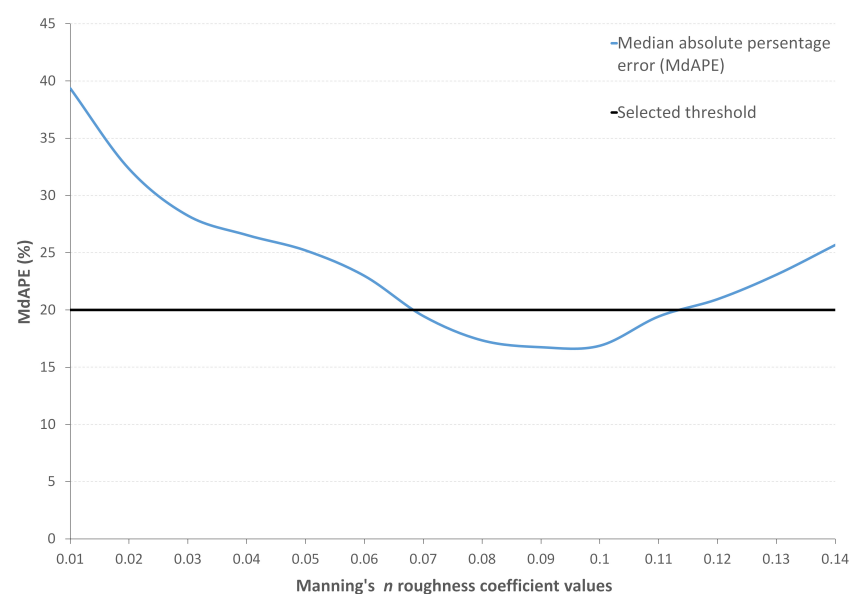

Figure 4. HEC-RAS model responses to changes in roughness coefficient values (Manning's $n$ ), in terms of Median Absolute Percentage Error (MdAPE) and selected threshold for acceptable behavioural models.

et al., 2016). In this study, qualitative (the Threat Score, TS or Critical Success Index, CSI) and quantitative criteria (such as the MSE, RMSE, MAE and Bias) have been included in the framework for accurate Monte-Carlo experiments. These statistical criteria are estimated from the observed flooded inundation area (Fig. 2) with the intersection of simulated flood extent at the study cross-sections.

Based on the input data discussed in the previous paragraphs and the specified user selection criteria, the framework iteratively assigns new roughness coefficient values based on LHS to HEC-RAS model for each simulation run. For each simulation run and the selected statistical criterion, calculated for each simulation between simulated and observed flood areal extent, the framework accepts or rejects the simulation and then is adjusted for a new simulation run with a new roughness $n$ value. The framework is terminated when the desired number of realizations for probabilistic flood inundation mapping is fulfilled (e.g. 1000 realizations). The Median Absolute Percentage Error (MdAPE) is selected because it is an unbiased quantitative statistical criterion (Hyndman and Koehler, 2006). The MdAPE, calculated for each simulation between simulated and observed flood areal extent, is defined as:

$\operatorname{MdAPE}=\operatorname{median}\left(\left|\frac{100\left(Y_{t}-F_{t}\right)}{Y_{t}}\right|\right)$

where $Y_{t}$ is the observed flood extent and $F_{t}$ is the simulated flood extent for all cross-setions.

Acceptable behavioural models are selected when MdAPE is lower than $20 \%$. This threshold is selected based on preliminary sensitivity analysis of the employed statistical criteria (not shown due to paper length limitations). Figure 4 shows MdAPE variation results with the roughness coefficient values (Manning's $n$ ) and the selected threshold for

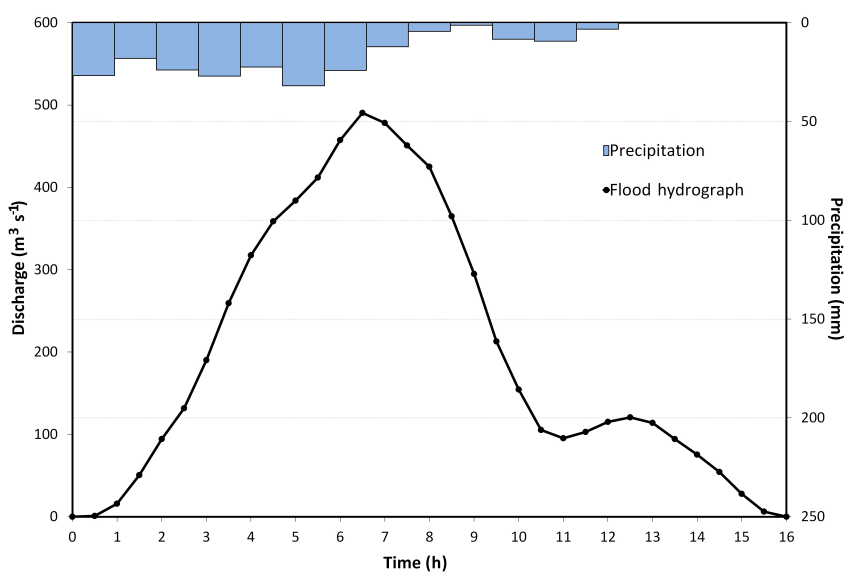

Figure 5. The rainfall hyetograph of the 9 October 2006 with the estimated CIUH flood hydrograph.

acceptable behavioural models. The post-processing stage in this study is the visualization process of the HEC-RAS Monte-Carlo framework. Due to large number of HEC-RAS outputs several scripts were built with the use of ModelBuilder in ArcGIS. The ultimate target was to transform HEC-RAS results to flood extent polygons and raster water depth files for obtaining probabilistic flood inundation maps due to roughness values. Finally, probability maps are generated for the acceptable realizations and the statistical criterion used.

\section{Results and Discussion}

The developed Monte-Carlo procedure (Fig. 1) is applied to the ungauged Xerias stream reach (Fig. 2). The 1-D HECRAS model is applied for probabilistic flood inundation mapping based on roughness coefficient values. The procedure is demonstrated for the observed historical flood event of the 9 October 2006. In the following paragraphs the estimation of input data, and the concurrent application of the HECRAS model within the HEC-RAS Monte-Carlo framework are presented and analysed.

\subsection{HEC-RAS model setup and input data estimation}

The estimation of the inflow flood hydrograph based on the implementation of the Clark Instantaneous Unit Hydrograph (CIUH) on the inlet of the study stream reach for the extreme observed rainfall hyetograph on that day gave the inflow flood hydrograph (Fig. 5). For that day total rainfall was $210 \mathrm{~mm}$ with $12 \mathrm{~h}$ duration which resulted in a flood episode with $490 \mathrm{~m}^{3} \mathrm{~s}^{-1}$ peak flow and a duration of $16 \mathrm{~h}$ (Fig. 5). Hence, this extreme event is characterised as a flash flood episode. Flash floods, a common type of floods in abundant Mediterranean catchments (Aronica et al., 2012), are categorized as the most devastating hazards concerning in- 
frastructures and mortality (Gruntfest and Handmer, 2001). This specific flood episode with an estimated return period of 100 years had major impacts on the study area causing significant damages to the primary and secondary sector (i.e. agricultural and industrial activities), transportation networks and other technical infrastructures (Papaioannou et al., 2015).

The estimation of roughness coefficient values based on the application of the pebble count survey with the measured cobble and gravel bed materials and the study empirical formulas that gave large bounds in the roughness coefficient values. Manning's $n$ values are ranging from 0.03 to 0.12 for the predefined size diameters of $d_{50}, d_{65}, d_{75}, d_{84}$ and $d_{94}$ (Table 1). Hence, nine theoretical probability distributions used on various Monte-Carlo experiments (Normal, Lognormal, Exponential, Gamma, Beta, Uniform, Logistic, Cauchy and Weibull) are applied to the estimated range values and checked using several goodness of fit criteria (Venables and Ripley, 2002; R Core Team, 2017). Figure 6 shows the cumulative distribution function of the fitted theoretical probability distributions to the estimated Manning's values. The empirical probability of the roughness values is also shown on Fig. 6. Based on this figure, the lognormal distribution followed by the Gamma distribution should be potential distributions to simulate the empirical probability distribution of Manning's values. However, it should be mentioned that due to the small sample of roughness values, Table 2 shows that the superiority of the above mentioned distributions is questionable. For example, if the judgment of the theoretical distribution is based on the Kolmogorov-Smirnov test, the Logistic and the Weibull distributions should be selected. Overall, as proven by the goodness of fit Akaike Information Criterion (AIC) and Bayesian Information Criterion (BIC) the Lognormal should be the first choice to resemble the empirical derived Manning's $n$ values. The Gamma distribution could be a potential alternative to the Lognormal theoretical distribution (Table 2).

\subsection{HEC-RAS Monte-Carlo framework application}

The developed framework is demonstrated for a specific test case. The test case is that the Lognormal distribution is able to simulate the empirical probability of the used theoretical equations which determine Manning's values based on particle size. Then, Latin Hypercube Sampling (LHS) is performed to generate large Manning roughness coefficients data sets for 1000 acceptable realisations.

The framework allows the selection of the subset of behavioural models that are then used to simulate the observed historical flood episode. Flood inundation probability maps are created with the inherent calibration process using MdAPE with a threshold tolerance of $20 \%$. Hence this study rejected all the models that have MdAPE larger than $20 \%$. Each simulation run is accepted or rejected according to the MdAPE and if rejected the framework is adjusted for a new

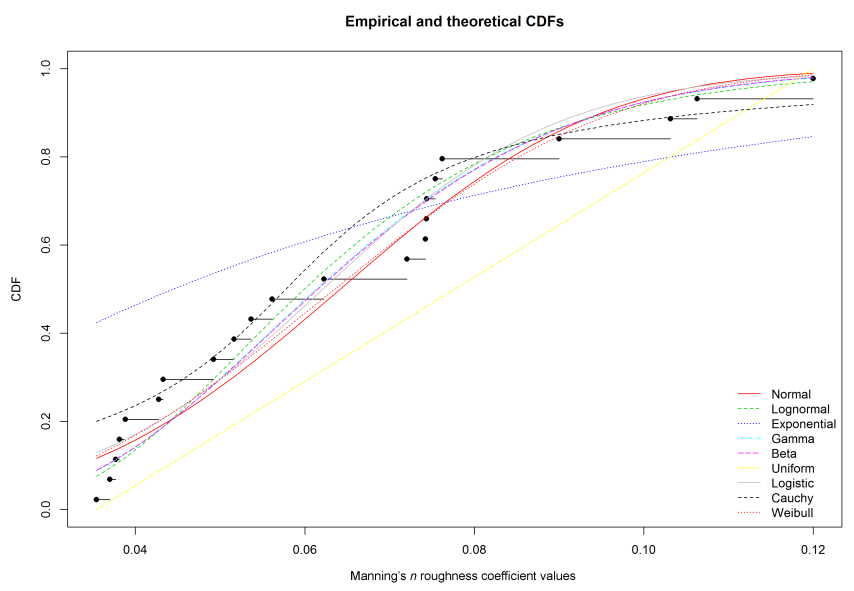

Figure 6. Distribution fitting on the empirical derived Manning's values.

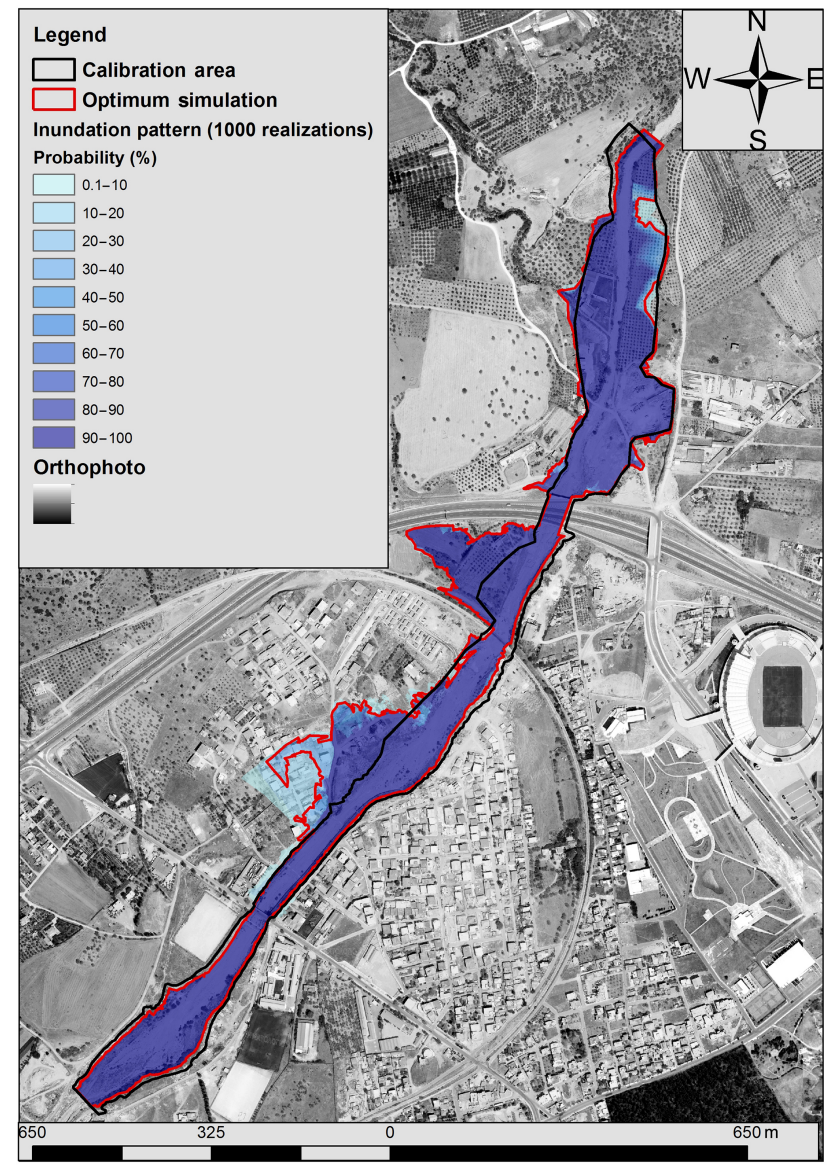

Figure 7. Probability of inundation using 1000 realizations and lognormal distribution in roughness coefficient generation.

simulation run with a new roughness $n$ value. If accepted then the framework saves the simulation and starts again a new simulation run. The framework is terminated when the desired number of realizations for probabilistic flood inun- 
dation mapping is fulfilled (1000 realizations in this test set). The results are then combined to produce an uncertain flood extent map. For the creation of the flood extent maps a binary wet-dry reasoning is selected in order to estimate the flood inundation probability for each cell. In particular, each acceptable realisation is attributed a likelihood weight in the range $[0,1]$ according to the MdAPE values. All probability maps created for each acceptable realization are summed to create the total one. Finally, the probability maps are created by dividing the total with the number of ensemble members and the probabilistic map is obtained by performing a weighted sum of each Monte Carlo simulation at each $i$ th cell (Horritt, 2006). Hence, for computational purposes the probability maps are classified in 10 probability classes: $0-10$, 10-20, 20-30, 30-40, 40-50, 50-60, 60-70, 70-80, 80-90, 90-100\%. Figure 7 shows the uncertain flood extent map obtained by combining the results and reflects the likelihood of inundation of any point for the observed flood event due the uncertainty of roughness values. In Fig. 7, inundated areas are overlaid with a high resolution aerial orthophoto to highlight spatial extension of the flooded areas in various probabilistic conditions for a better understanding of the flooding hazard. In the same figure the deterministic application of HEC-RAS is also depicted as the optimum simulation (red boundary area in Fig. 7) for comparison purposes. Deterministic flood inundation maps are typically used to classify floodplains into two distinct regions of wet (flooded) and dry areas. This binary map is produced by calibration of the HEC-RAS model. Manual calibration was performed by trial and error to simulate this historical flood inundation event and to get an estimation of the average Manning's $n$ value for the study river reach. Since, during this episode official flood extent data were not available, the only evidence used for calibration was an inundation extent map developed in previous studies (black boundary area in Fig. 7). It should be mentioned that the deterministic and stochastic maps cannot be directly compared (Kiczko et al., 2013). However for comparison purposes, the deterministic flood inundation map is assumed to represent flooded areas with a probability of exceedance of 0.5. Based on this deterministic simulation the MdAPE is estimated as $16 \%$ with average estimated Manning's $n$ value equal to 0.09 (Table 1).

It should be mentioned that the proposed framework is developed for application in gravel-bed and cobble-bed streams which are typical characteristics of flash flood events in mountainous and semi-mountainous watersheds. It takes into account only the uncertainty of roughness coefficient values and neglects all other sources of uncertainty (e.g. input data uncertainty such as design flood, DEM errors, channel geometry and model uncertainty such as 1-D, 2-D model structure, and model parameterisation). Furthermore, extensive testing of the framework is required for general application at ungauged rivers (e.g. use of other theoretical distributions for describing the roughness values, number of acceptable solutions, use and acceptable tolerance of other employed statisti- cal criteria). Furthermore, the application of the deterministic and probabilistic approach in the same study area highlights and exemplifies the pros and cons of the two methods for floodplain mapping at ungauged watersheds. For more details, the reader is referred to recent studies and references therein (Di Baldassarre et al., 2010; Dottori, et al., 2013; Alfonso et al., 2016). These studies showed that the calibration process of a hydraulic model on a historical event with a specified return period could give poor results in flood inundation mapping due to the uncertainty in model parameters when applied in other synthetic design flood hydrographs. Therefore, probabilistic approaches should be followed which are less sensitive to the non-stationarity of model parameters (Di Baldassarre et al., 2010).

\section{Concluding Remarks}

A probabilistic procedure for floodplain inundation mapping is developed and analysed for the ungauged Xerias stream reach, Volos, Greece. The developed process evaluates the uncertainty introduced by the roughness coefficient values on hydraulic models in flood inundation modelling and mapping. The well-established hydraulic model, HEC-RAS 1-D is selected and linked to Monte-Carlo simulations of hydraulic roughness. Terrestrial Laser Scanner data have been used to produce a high quality DEM for input data uncertainty minimisation and to improve representation accuracy of stream channel topography required by the hydraulic model. Initial Manning's n roughness coefficient values are based on pebble count field surveys and empirical formulas. Various theoretical probability distributions are fitted and evaluated on their accuracy to represent the estimated roughness values. Finally, Latin Hypercube Sampling has been used for generation of different sets of Manning roughness values and flood inundation probability maps have been created with the use of Monte Carlo simulations. Historical flood extent data, from an extreme historical flash flood event, are used for the validation of the method. The calibration process is based on a binary wet-dry reasoning with the use of Median Absolute Percentage Error evaluation metric. The results of this study support probabilistic flood hazard mapping and provide water resources managers with valuable information for planning and implementing flood risk mitigation strategies. However, extensive testing of the procedure in a probabilistic framework is required for general application at ungauged stream reaches.

Finally, deterministic and probabilistic approaches for flood inundation mapping at ungauged rivers are compared and evaluated in this study. The simulated flood hydrograph which corresponds to a specific return period and the Manning's roughness values used to map the flooded spatial extent are affected by significant uncertainty in their estimation. Based on these conditions, visualising flood hazard in a study reach as a probability map seems to be more correct 
than a deterministic assessment. Hence, probability maps for mapping flood extent are attractive ways of flooding likelihood visualisation and add extra credibility in their estimation. Flood inundation prediction under different probabilistic scenarios could assist in floodplain risk management and to minimize the social and economic impacts of floods.

Data availability. Data for this study are available upon request from George Papaioannou (gpapaioa@uth.gr). The Lidar data used where obtained through field survey with the Optech ILRIS 3D laser scanner. Rainfall data for the flood event of 9 October 2006 are available from the Institute of Industrial Plants and Livestock/Department of Plant Protection in Volos, Greece (http://www. ipsw.gr/en/departments/plant-protection-volos).

Competing interests. The authors declare that they have no conflict of interest.

Acknowledgements. The authors would like to thank the guest topical editor Giuliano Di Baldassarre, Renata J. Romanowicz and an anonymous reviewer for their constructive and useful comments which contributed to an improved presentation of the paper.

Edited by: G. Di Baldassarre

Reviewed by: R. Romanowicz and one anonymous referee

\section{References}

Aggett, G. R. and Wilson, J. P.: Creating and coupling a highresolution DTM with a 1-D hydraulic model in GIS for scenariobased assessment of avulsion hazard in gravel-bed river, Geomorphology, 113, 21-34, 2009.

Alfieri, L., Salamon, P., Bianchi, A., Neal, J., Bates, P., and Feyen, L.: Advances in pan-European flood hazard mapping, Hydrol. Process., 28, 4067-4077, 2014.

Alfonso, L., Mukolwe, M. M., and Di Baldassarre, G.: Probabilistic Flood Maps to support decision-making: Mapping the Value of Information, Water Resour. Res., 52, 1026-1043, doi:10.1002/2015WR017378, 2016.

Apel, H., Thieken, A. H., Merz, B., and Blöschl, G.: Flood risk assessment and associated uncertainty, Nat. Hazards Earth Syst. Sci., 4, 295-308, doi:10.5194/nhess-4-295-2004, 2004.

Apel, H., Aronica, G. T., Kreibich, H., and Thieken, A. H.: Flood risk analyses - how detailed do we need to be?, Nat. Hazards, 49, 79-98, doi:10.1007/s11069-008-9277-8, 2009.

Aronica, G. T., Bates, P. D., and Horritt, M. S.: Assessing the uncertainty in distributed model predictions using observed binary pattern information within GLUE, Hydrol. Process., 16, 20012016, doi:10.1002/hyp.398, 2002.

Aronica, G. T., Brigandí, G., and Morey, N.: Flash floods and debris flow in the city area of Messina, north-east part of Sicily, Italy in October 2009: the case of the Giampilieri catchment, Nat. Hazards Earth Syst. Sci., 12, 1295-1309, doi:10.5194/nhess-121295-2012, 2012.
Bates, P. D., Horritt, M. S., Aronica, G., and Beven, K.: Bayesian updating of flood inundation likelihoods conditioned on flood extent data, Hydrol. Process., 18, 3347-3370, 2004.

Bates, P. D., Wilson, M. D., Horritt, M. S., Mason, D. C., Holden, N., and Currie, A.: Reach scale floodplain inundation dynamics observed using airborne synthetic aperture radar imagery: data analysis and modelling, J. Hydrol., 328, 306-318, 2006.

Brunner, G. W.: HEC-RAS River Analysis System: Hydraulic Reference Manual, Version 5.0, US Army Corps of Engineers - Hydrologic Engineering Center, 2016a.

Brunner, G. W.: HEC-RAS River Analysis System: User's Manual, Version 5.0, US Army Corps of Engineers - Hydrologic Engineering Center, 2016b.

Bunte, K., Abt, S. R., Potyondy, J. P., and Swingle, K. W.: Comparison of three pebble count protocols (EMAP, PIBO, and SFT) in two mountain gravel-bed streams, J. Am. Water Resour. Assoc., 45, 1209-1227, doi:10.1111/j.1752-1688.2009.00355.x, 2009.

Chang, M.: Forest Hydrology: An Introduction to Water and Forests, 1st Edn., CRC Press, Taylor and Francis Group, Boca Raton, Florida, USA, 2002.

Chow, V. T.: Open-Channel Hydraulics, McGraw-Hill, New York, 1959.

Clark, C. O.: Storage and the unit hydrograph, Trans. ASCE, 110, 1419-1446, 1945.

Cook, A. and Merwade, V.: Effect of topographic data, geometric configurations and modeling approach on flood inundation mapping, J. Hydrol., 377, 131-142, 2009.

Coon, W. F.: Estimation of roughness coefficients for natural stream channels with vegetated banks, Geological Survey (US), New York (State), Dept. of Transportation, 1998.

Costabile, P. and Macchione, F.: Enhancing river model set-up for 2-D dynamic flood modelling, Environ.1 Modell. Softw., 67, 89107, 2015.

Di Baldassarre, G., Schumann, G., Bates, P. D., Freer, J. E., and Beven, K. J.: Floodplain mapping: a critical discussion on deterministic and probabilistic approaches, Hydrol. Sci. J., 55, 364376, 2010.

Dimitriadis, P., Tegos, A., Oikonomou, A., Pagana, V., Koukouvinos, A., Mamassis, N., Koutsoyiannis, D., and Efstratiadis, A.: Comparative evaluation of 1-D and quasi-2-D hydraulic models based on benchmark and real-world applications for uncertainty assessment in flood mapping, J. Hydrol., 534, 478-492, 2016.

Domeneghetti, A., Vorogushyn, S., Castellarin, A., Merz, B., and Brath, A.: Probabilistic flood hazard mapping: effects of uncertain boundary conditions, Hydrol. Earth Syst. Sci., 17, 31273140, doi:10.5194/hess-17-3127-2013, 2013.

Dottori, F., Di Baldassarre, G., and Todini, E.: Detailed data is welcome, but with a pinch of salt: Accuracy, precision, and uncertainty in flood inundation modelling, Water Resour. Res., 49, 6079-6085, doi:10.1002/wrcr.20406, 2013.

Goodell, C.: Breaking the HEC-RAS code: A user's guide to automating HEC-RAS, h21s, Portland, USA, 2014.

Gruntfest, E. and Handmer, J.: Coping with Flash Floods, NATO Science Series, 77, 2001.

Gwinn, W. R. and Ree W. O.: Maintenance effects on the hydraulic properties of a vegetation lined channel, ASAE Trans., 23, 63642, doi:10.13031/2013.34637, 1980.

Hall, J., Arheimer, B., Borga, M., Brázdil, R., Claps, P., Kiss, A., Kjeldsen, T. R., Kriauciuniene, J., Kundzewicz, Z. W., Lang, 
M., Llasat, M. C., Macdonald, N., McIntyre, N., Mediero, L., Merz, B., Merz, R., Molnar, P., Montanari, A., Neuhold, C., Parajka, J., Perdigão, R. A. P., Plavcová, L., Rogger, M., Salinas, J. L., Sauquet, E., Schär, C., Szolgay, J., Viglione, A., and Blöschl, G.: Understanding flood regime changes in Europe: a state-of-the-art assessment, Hydrol. Earth Syst. Sci., 18, 27352772, doi:10.5194/hess-18-2735-2014, 2014.

Ho, C. W. and Huang, H. P.: Manning's roughness coefficient of mountainous streams in Taiwan, in: Channel flow resistance: centennial of Manning's formula, edited by: Yen, B. C., Littleton: Water Resources Publications, 299-308, 1992.

Horritt, M. S.: A methodology for the validation of uncertain flood inundation models, J. Hydrol., 326, 153-165, 2006.

Horritt, M. S. and Bates, P. D.: Predicting floodplain inundation: raster-based modelling versus the finite element approach, Hydrol. Process., 15, 825-842, doi:10.1002/hyp.188, 2001.

Horritt, M. S. and Bates, P. D.: Evaluation of 1-D and 2-D numerical models for predicting river flood inundation, J. Hydrol., 268, 8799, 2002.

Horritt, M. S., Di Baldassarre, G., Bates, P. D., and Brath, A.: Comparing the performance of 2-D finite element and finite volume models of floodplain inundation using airborne SAR imagery, Hydrol. Process., 21, 2745-2759, 2007.

Hyndman, R. J. and Koehler, A. B.: Another look at measures of forecast accuracy, Int. J. Forecasting, 22, 679-688, doi:10.1016/j.ijforecast.2006.03.001, 2006.

Jarrett, R. D.: Determination of roughness coefficients for streams in Colorado. Water Res. Investigations Report 85-4004, Geological Survey (US), Lakewood, Colorado, USA, 1985.

Javan, M., McKeogh E. J., and Kiely, G. K.: Field evaluation of Manning's $\mathrm{n}$ in gravel rivers, in: Channel flow resistance: centennial of Manning's formula, edited by: Yen, B. C., Littleton: Water Resources Publications, 318-327, 1992.

Kiczko, A., Romanowicz, R. J., Osuch, M., and Karamuz, E.: Maximising the usefulness of flood risk assessment for the River Vistula in Warsaw, Nat. Hazards Earth Syst. Sci., 13, 3443-3455, doi:10.5194/nhess-13-3443-2013, 2013.

Kourgialas, N. N. and Karatzas, G. P.: A hydro-sedimentary modeling system for flash flood propagation and hazard estimation under different agricultural practices, Nat. Hazards Earth Syst. Sci., 14, 625-634, doi:10.5194/nhess-14-625-2014, 2014.

Liu, Q., Qin, Y., Zhang, Y., and Li, Z.: A coupled 1D-2D hydrodynamic model for flood simulation in flood detention basin, Nat. Hazards, 75, 1303-1325, doi:10.1007/s11069-014-1373-3, 2015.

Loukas, A. and Quick, M. C.: Physically-based estimation of lag time for forested mountainous watersheds, Hydrolog. Sci. J., 41, 1-19, doi:10.1080/02626669609491475, 1996.

Marcus, W. A., Roberts, K., Harvey, L., and Tackman, G.: An evaluation of methods for estimating Manning's $n$ in small mountain streams, Mt. Res. Dev., 12, 227-239, 1992.

Marzocchi, R., Federici, B., Cannata, M., Cosso, T., and Syriou, A.: Comparison of one-dimensional and two-dimensional GRASSGIS models for flood mapping, Appl. Geomatics, 6, 245-254, doi:10.1007/s12518-014-0140-1, 2014.

McCuen, R. H.: Hydrologic Analysis and Design, 3rd Edn., Pearson, 2005

McKay, M. D., Beckman, R. J., and Conover, W. J.: A comparison of three methods for selecting values of input variables in the analysis of output from a computer code, Technometrics, 21, 239-245, 1979.

McKay, S. K. and Fischenich, J. C.: Robust prediction of hydraulic roughness. Vicksburg, Miss: US Army Engineer Research and Development Center, 2011.

Merz, B. and Thieken, A. H.: Separating natural and epistemic uncertainty in flood frequency analysis, J. Hydrol., 309, 114-132, doi:10.1016/j.jhydrol.2004.11.015, 2005.

Md Ali, A., Solomatine, D. P., and Di Baldassarre, G.: Assessing the impact of different sources of topographic data on 1-D hydraulic modelling of floods, Hydrol. Earth Syst. Sci., 19, 631643, doi:10.5194/hess-19-631-2015, 2015.

Millard, S. P.: EnvStats: An R Package for Environmental Statistics, Springer, New York, 2013.

Noman, N. S., Nelson, E. J., and Zundel, A. K.: Review of automated floodplain delineation from digital terrain models, J. Water Res. Pl.-ASCE, 127, 394-402, 2001.

Noman, N. S., Nelson, E. J., and Zundel, A. K.: Improved process for floodplain delineation from digital terrain models, J. Water Res. Pl.-ASCE, 129, 427-436, 2003.

Papaioannou, G., Loukas, A., and Georgiadis, Ch.: The effect of riverine terrain spatial resolution on flood modeling and mapping, Proc. SPIE 8795, First International Conference on Remote Sensing and Geoinformation of the Environment (RSCy2013), 87951H, doi:10.1117/12.2028218, 2013.

Papaioannou, G., Loukas, A., Vasiliades, L., and Aronica G. T.: Flood inundation mapping sensitivity to riverine spatial resolution and modelling approach, Nat. Hazards, 83, 117-132, doi:10.1007/s11069-016-2382-1, 2016.

Papaioannou, G., Vasiliades, L., and Loukas, A.: Multi-criteria analysis framework for potential flood prone areas mapping, Water Resour. Manag., 29, 399-418, doi:10.1007/s11269-014-0817-6, 2015.

Pappenberger, F., Beven, K., Horritt, M., and Blazkova, S.: Uncertainty in the calibration of effective roughness parameters in HEC-RAS using inundation and downstream level observations, J. Hydrol., 302, 46-69, doi:10.1016/j.jhydrol.2004.06.036, 2005.

Podhoranyi, M. and Fedorcak, D.: Inaccuracy introduced by LiDAR-generated cross sections and its impact on 1-D hydrodynamic simulations, Environ. Earth Sci., 73, 1-11, doi:10.1007/s12665-014-3390-7, 2015.

R Core Team: R: A language and environment for statistical computing, R Foundation for Statistical Computing, Vienna, Austria, available at: https://www.R-project.org/, last access: 2 March 2017.

Romanowicz, R. J. and Kiczko, A.: An event simulation approach to the assessment of flood level frequencies: risk maps for the Warsaw reach of the River Vistula, Hydrol. Process., 30, 24512462, doi:10.1002/hyp.10857, 2016.

Romero, M., Revollo, N., and Mollina, J.: Flow resistance in steep mountain rivers in Bolivia, J. Hydrodyn., 22, 702-707, doi:10.1016/S1001-6058(10)60018-2, 2010.

Sampson, C. C., Fewtrell. J. T., Duncan. A., Shaad. K., Horritt, S. M., and Bates, D. P.: Use of terrestrial laser scanning data to drive decimetric resolution urban inundation models, Adv. Water Resour., 41, 1-17, doi:10.1016/j.advwatres.2012.02.010, 2012.

Sarhadi, A., Soltani, S., and Modarres, R.: Probabilistic flood inundation mapping of ungauged rivers: Linking GIS tech- 
niques and frequency analysis, J. Hydrol., 458-459, 68-86, doi:10.1016/j.jhydrol.2012.06.039, 2012.

Shen, D., Wang, J., Cheng, X., Rui, Y., and Ye, S.: Integration of 2-D hydraulic model and high-resolution lidar-derived DEM for floodplain flow modeling, Hydrol. Earth Syst. Sci., 19, 36053616, doi:10.5194/hess-19-3605-2015, 2015.

Teng, J., Vaze, J., Dutta, D., and Marvanek, S.: Rapid inundation modelling in large floodplains using LiDAR DEM, Water Resour. Manag., 29, 2619-2636, doi:10.1007/s11269-015-0960-8, 2015.

Teng, J., Jakeman, A. J., Vaze, J., Croke, B. F. W., Dutta, D., and Kim, S.: Flood inundation modelling: A review of methods, recent advances and uncertainty analysis, Environ. Modell. Softw., 90, 201-216, doi:10.1016/j.envsoft.2017.01.006, 2017.

Tsakiris, G.: Flood risk assessment: concepts, modelling, applications, Nat. Hazards Earth Syst. Sci., 14, 1361-1369, doi:10.5194/nhess-14-1361-2014, 2014.
Tsakiris, G. and Bellos, V.: A numerical model for two-dimensional flood routing in complex terrains, Water Resour. Manage., 28, 1277-1291, doi:10.1007/s11269-014-0540-3, 2014.

Tsubaki, R. and Fujita, I.: Unstructured grid generation using LiDAR data for urban flood inundation modelling, Hydrol. Process., 24, 1404-1420, doi:10.1002/hyp.7608, 2010.

Ugarte, A. S. and Madrid-Aris, M.: Roughness Coefficient in mountain river, in: Hydraulic Engineering, edited by: Cotroneo, G. V. and Rumer, R., 94, New York: American Society of Civil Engineers, 652-656, 1994.

Venables, W. N. and Ripley, B. D.: Modern Applied Statistics with S, 4th Edn., Springer, New York, 2002.

Ward, A. D., Trimble, S. W., Burckhard, S. R., and Lyon, J. G.: Environmental Hydrology, 3rd Edn., CRC Press, 2016. 